\title{
Identification of hair shaft progenitors that create a niche for hair pigmentation
}

\author{
Chung-Ping Liao, ${ }^{1}$ Reid C. Booker, ${ }^{1}$ Sean J. Morrison, ${ }^{2,3,4,5,6}$ and Lu Q. Le ${ }^{1,4,5}$ \\ ${ }^{1}$ Department of Dermatology, ${ }^{2}$ Department of Pediatrics, ${ }^{3}$ Children's Research Institute, ${ }^{4}$ Simmons Comprehensive Cancer \\ Center, ${ }^{5}$ Hamon Center for Regenerative Science and Medicine, ${ }^{6}$ Howard Hughes Medical Institute, University of Texas \\ Southwestern Medical Center, Dallas, Texas 75390, USA
}

\begin{abstract}
Hair differentiates from follicle stem cells through progenitor cells in the matrix. In contrast to stem cells in the bulge, the identities of the progenitors and the mechanisms by which they regulate hair shaft components are poorly understood. Hair is also pigmented by melanocytes in the follicle. However, the niche that regulates follicular melanocytes is not well characterized. Here, we report the identification of hair shaft progenitors in the matrix that are differentiated from follicular epithelial cells expressing transcription factor KROX20. Depletion of Krox20 lineage cells results in arrest of hair growth, confirming the critical role of $\mathrm{KROX}^{+} \mathrm{C}^{+}$cells as antecedents of structural cells found in hair. Expression of stem cell factor (SCF) by these cells is necessary for the maintenance of differentiated melanocytes and for hair pigmentation. Our findings reveal the identities of hair matrix progenitors that regulate hair growth and pigmentation, partly by creating an SCF-dependent niche for follicular melanocytes.
\end{abstract}

[Keywords: stem cell factor (SCF); hair pigmentation; hair shaft progenitor cell; hair follicle stem cell; hair matrix; KROX20]

Supplemental material is available for this article.

Received March 10, 2017; revised version accepted April 13, 2017.

Hair is a highly keratinized tissue differentiated from hair follicle (HF) stem cells, which are located primarily in a discrete reservoir called the bulge (Cotsarelis et al. 1990; Blanpain et al. 2004; Tumbar et al. 2004). The cycle of hair growth and involution occurs in three phases: anagen (growth), catagen (regression), and telogen (resting) (Blanpain and Fuchs 2009; Shimomura and Christiano 2010; Plikus et al. 2012; Solanas and Benitah 2013; Watt 2014). Hair is commonly pigmented because of the presence of melanin in hair shafts, which in turn is synthesized by follicular melanocytes and then transferred to the neighboring hair progenitors that give rise to hair shafts (Nishimura et al. 2002, 2005; Lin and Fisher 2007). Despite recent advances in our understanding of HF stem cell biology, the mechanisms that regulate hair pigmentation remain poorly understood, especially with respect to the cellular interactions between hair progenitor cells and melanocytes that take place in the HF matrix.

Stem cell factor (SCF, also known as KIT ligand or Steel factor) is a growth factor that regulates multiple physiological homeostatic events, including the maintenance of hematopoietic stem cells (Ding et al. 2012), mast cells (Lennartsson and Ronnstrand 2012), and melanocytes (Lennartsson and Ronnstrand 2012). The critical role of

Corresponding author: lu.le@utsouthwestern.edu

Article published online ahead of print. Article and publication date are online at http://www.genesdev.org/cgi/doi/10.1101/gad.298703.117. Freely available online through the Genes \& Development Open Access option.
SCF and its receptor, KIT, for hair pigmentation has been supported by the absence of hair pigment in several SCF- and KIT-deprived animals (Copeland et al. 1990; Reith et al. 1990; Kunisada et al. 1998b; Botchkareva et al. 2001; Nishimura et al. 2002). It is apparent that melanocytes are the relevant target cells in this type of hypopigmentation, as they are the melanin-producing cells as well as the predominant KIT-expressing cell in the HF. However, the sources of SCF that support melanocytic activity in the HF have not been fully characterized, although SCF expression by cells in the dermal papilla has been suggested to promote melanocyte stem cell differentiation (Chang et al. 2013).

The HF matrix is composed of epithelial cells surrounding the dermal papilla. The HF matrix cells proliferate and differentiate into the structures of the hair shaft and inner root sheath (Driskell et al. 2011). There are also melanocytes residing in the same niche to provide melanin to hair shaft progenitor cells for hair pigmentation. A dominant population of matrix cells is transit-amplifying cells. They proliferate rapidly for several divisions and then progress upward to become committed progenitors that differentiate into central hair shafts (the medulla, cortex, and cuticle), its surrounding channels or the inner root sheaths (the cuticle, Henle, and Huxley layers) that guide

(C) 2017 Liao et al. This article, published in Genes \& Development, is available under a Creative Commons License (Attribution 4.0 International), as described at http://creativecommons.org/licenses/by/4.0/. 
hair shafts toward the skin surface, and the companion layer (the innermost layer of the outer root sheath) (Hsu et al. 2011, 2014). In contrast to HF stem cells in the bulge, the identities of the committed progenitor cells that give rise directly to hair shafts (the medulla, cortex and cuticle) are currently not well characterized. In addition, the development of hair is also accompanied by pigmentation that is contributed to the hair shafts by melanocytes. The reciprocal interactions between melanocytes and hair progenitor cells as well as the source of SCF, which regulates hair pigmentation, are not well characterized.

KROX20 (also known as EGR2) is a zinc finger transcription factor that regulates hindbrain segmentation (Schneider-Maunoury et al. 1993), Schwann cell myelination (Topilko et al. 1994), and lymphocyte immune responses (Li et al. 2012). In addition, KROX20 is expressed in subpopulations of HF cells (Gambardella et al. 2000). However, the role of the KROX20-expressing cells in HF development is not known. We now report that the transcription factor KROX20 identifies a sublineage of HF epithelial cells toward the differentiation of hair shaft during HF morphogenesis. We observed that they are a necessary source of SCF for the maintenance of mature melanocytes in the hair matrix to produce hair pigmentation, as evidenced by the complete loss of pigment when $S c f$ is deleted in Krox20 lineage cells. We also demonstrate that deletion of Krox20 lineage cells in vivo results in a complete arrest of new hair growth, demonstrating the critical role of Krox20 lineage cells in hair development.

\section{Results}

\section{Mice lacking SCF in Krox20 lineage cells exhibit progressive hair graying}

While studying the role of mast cells and SCF during the initiation of neurofibroma, a Schwann cell neoplasm, we conditionally deleted $S c f$ in neurofibroma neoplastic cells using the Schwann cell lineage Krox20Cre mouse line. Serendipitously, we found that the mice without SCF in Krox20 lineage cells developed hair graying and, early in life, lost all hair pigmentation. Invariably, all Scflox/gfp; Krox20Cre mice $(n=20)$ displayed progressive hair graying. The first round of hair graying occurred homogenously during postnatal days 30-40 (P30-P40). As the mice aged, the hairs underwent further depigmentation in waves. This change converted all black pigmented hairs to white within $9 \mathrm{mo}$ (Fig. 1A; Supplemental Fig. S1A). We believe that this pattern of hair color change is associated with the mouse hair cycle when old hairs are replaced by newly generated hairs (Plikus and Chuong 2008; Shimomura and Christiano 2010).

To characterize the cause of hair graying in the $S c f^{f l o x / g f p}$; Krox20Cre mice, we first analyzed the pelage hair shafts plucked from P20 dorsal skin. Interestingly, the amount of pigment at the distal and proximal ends of each hair shaft was quite different; the amount of pigment at the distal appeared normal, but the pigment was mostly absent from the proximal end (Fig. 1B). FontanaMasson staining confirmed that this hypopigmentation was caused by the absence of melanin in the hair shaft cortex and medulla (the compartments housing the most melanin in pigmented hair shaft) (Fig. 1C). We then determined the time of onset of decreased pigmentation. The amount of pigment in individual hairs appeared normal at P9 (Fig. 1D), with the loss of hair pigmentation becoming noticeable at P11; it progressed quickly after that (Fig. $1 \mathrm{D}, \mathrm{E})$. Analysis of melanin density in the HF revealed significant reductions at $\mathrm{P} 11$ and $\mathrm{P} 13(P<0.0001)$ (Fig. $1 \mathrm{~F})$, explaining the early loss of hair pigmentation in $S c f^{\text {flox } / g f p}$; Krox20Cre mice (Fig. 1B). Scflox/gfp; Krox20Cre mice exhibited progressive hair graying; their coat color underwent a dynamic change from black to white within 9 mo (Fig. 1A; Supplemental Fig. S1A). However, their newly synthesized hairs were already largely depigmented at P20 (Fig. 1B). These results suggested that the long period of hair graying is due to the mixture of partly pigmented (old) and unpigmented (new) hair shafts (Supplemental Fig. S1B,C) rather than the continuous production of new gray hairs. To confirm this, gray $S c f^{\text {flox/gfp}} ;$ Krox $20 C r e$ mice were depilated at 2 mo to remove all hairs, including old hairs, and stimulate new hair regeneration; as expected, their new hairs showed a complete loss of pigmentation (Fig. 1G). Most importantly, the fact that $S$ fflox/gfp; $^{\text {f }}$ Krox20Cre mice underwent a complete loss of hair pigmentation suggested that Krox20 lineage cells are the main source of SCF for follicular melanocytes to produce hair pigment.

\section{Hair pigmentation is dependent on SCF expression by epithelial keratinocytes}

In order to identify the cell type that produces SCF in the skin, thereby regulating hair pigmentation and being responsible for the hair hypopigmentation in $S c f$ flox/gfp; Krox20Cre mice, we examined the hair color phenotype of SCF ablation in different cell lineages in the skin by using several cell type-specific Cre mouse lines, including DhhCre (Schwann cell), PLPCre ${ }^{E R T 2}$ (Schwann cell), Tyr$\mathrm{Cre}^{E R T 2}$ (melanocyte), and K14Cre (keratinocyte). In addition, CMVCre $e^{E R T}$ (all cells) was included as a control for the inducible Cre systems. The R26-LacZ reporter was introduced into all of the above conditional knockouts to validate Cre expression specificity and efficiency.

In mice lacking SCF in Schwann cells (Scflox/gfp; DhhCre), we did not observe any hair color changes for up to $6 \mathrm{mo}$ (Fig. 2A). LacZ staining confirmed the specific DhhCre expression in Schwann cells in cutaneous nerves (Fig. 2B). Similar results were observed in Scfflox/gfp; PLPCre $e^{E R T 2}$ mice (Supplemental Fig. S2A). These results revealed that hair pigmentation does not depend on SCF expression in cells of Schwann cell lineages. Likewise, mice with SCF depletion in melanocytes $\left(S c f^{f l o x} / g f p\right.$; Tyr$C r e^{E R T 2}$ ) had no phenotype in hair color (Fig. 2C) after validation of Cre expression in the hair matrix melanocytes (Fig. 2D). Importantly, this result ruled out the possibility of melanocyte cell-autonomous SCF contributions to hair pigmentation. 
A

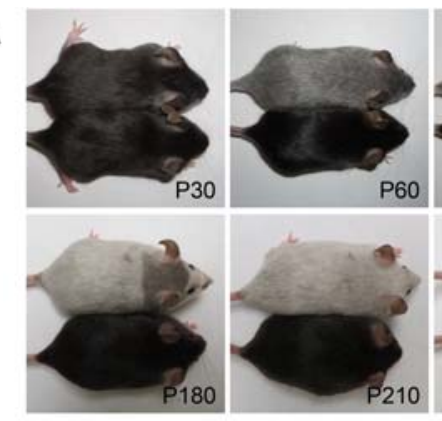

D

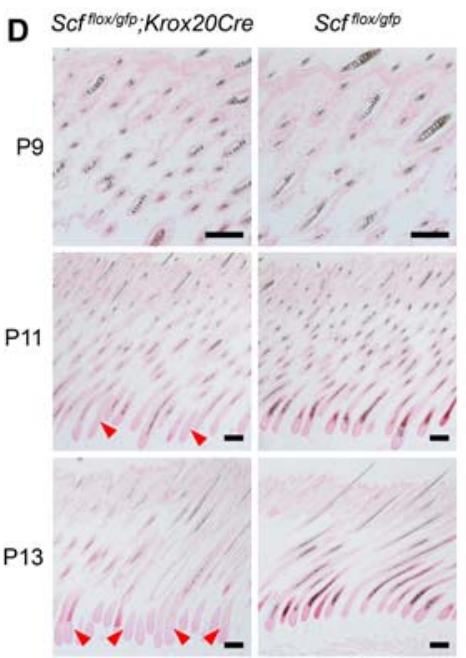

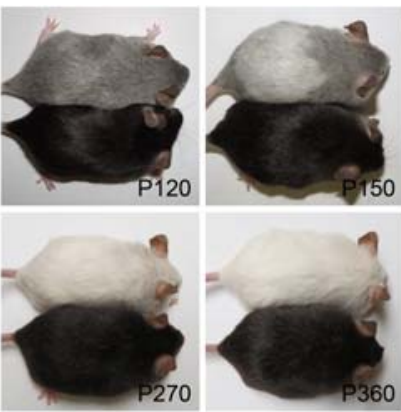

E

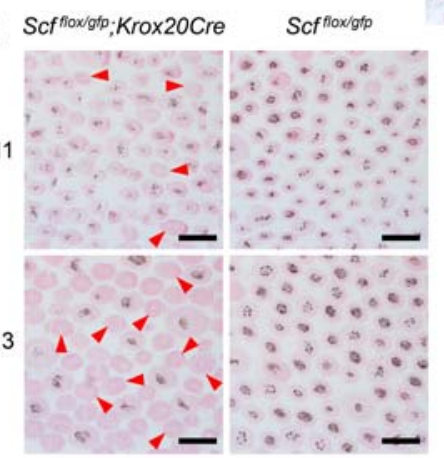

G

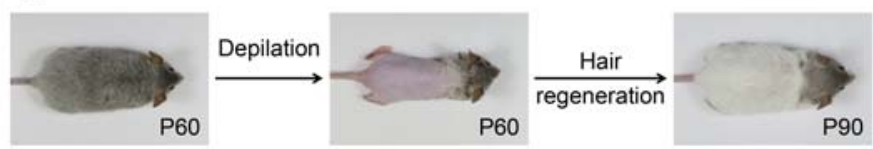

Figure 1. Mice lacking SCF in Krox20 lineage cells exhibit progressive hair graying. (A) A representative Scflox /gfp; Krox20Cre mouse (top) displaying hair graying along with aging as compared with a littermate $S c f^{f l o x} / g f p$ control $($ bottom) $n=20$. (B) Pelage hairs plucked from P20 Scflox/gfp; Krox20Cre mice showed distinct pigment levels in distal and proximal ends; newly developed hairs in the proximal side (arrowheads) were absent of pigment. $(C)$ Fontana-Masson staining confirmed the absence of melanin in the newly synthesized hairs (arrowheads) in P32 Scfflox/gfp; Krox20Cre mice. (D) HF section revealing normal hair pigmentation in Scfflox/gfp; Krox20Cre mice at P9 followed by a rapid loss of pigmentation beginning from the hair matrix (arrowheads) at P11 and P13. (E) Transverse HF section revealing hypopigmented hair shafts (arrowheads) in Scflox/gfp; Krox20Cre mice at P11 and P13. (F) Quantification and statistical analysis of $E$ showing a significant reduction of melanin density in $S c f^{f l o x / g f p}$; Krox20Cre graying hair shafts. Melanin density was analyzed by ImageJ. Data are mean \pm SEM from 100 randomly selected HFs in each group. $\left(^{* * * *}\right) P<0.0001$. $(G)$ Gray $S c f^{f l o x / g f p}$; Krox20Cre mice were depilated to stimulate hair regeneration; new hair shafts were completely absent of pigment. $n=3$. Nuclei were stained with nuclear Fast Red in C-E. Bar, $100 \mu \mathrm{m}$.

In Scflox/gfp; PLPCre $e^{E R T 2}$ and Scflox/gfp; TyrCre $e^{E R T 2}$ mice, we activated Cre expression by injecting 4-hydroxytamoxifen at P0. To be certain that this timing was suitable for examining the requirement for SCF in hair pigmentation, we generated Scflox/flox; CMVCre $e^{E R T}$ mice as a control to ablate $S c f$ ubiquitously by the same 4-hydroxytamoxifen induction condition. These mice lost their hair pigmentation nearly completely after the use of 4-hydroxytamoxifen (Fig. 2E), validating the Cre induction conditions. Similar results were also observed when these Cre expressions were induced in adult mice (Supplemental Fig. S2D-G).

Finally, we generated $S f^{f l o x} / g f p$; K14Cre mice to examine the phenotype after SCF ablation in keratinocytes. Strikingly, depletion of SCF in keratinocytes resulted in mice displaying a complete absence of hair pigmentation, beginning at birth (Fig. 2F), and this phenotype was limited to hair pigmentation without affecting the develop- ment or growth of hair and the epidermis (Fig. 2G). This result demonstrated the critical contribution of SCF from epithelial keratinocytes to hair pigmentation. This finding also supports the non-cell-autonomous SCF signaling model for hair pigmentation.

In addition, albeit with different timing of onset, aged Scflox/gfp; Krox20Cre mice phenocopied Scfllox/gfp; K14Cre mice by having a complete absence of hair pigmentation (Figs. 1A, 2F), suggesting that KROX20-expressing cells originate from K14 lineage epithelial keratinocytes and that KROX20 expression in the HF starts later in development.

\section{Dynamic localization of Krox20 lineage cells during HF morphogenesis}

To characterize the late onset of hair hypopigmentation in $S c f^{\text {flox } / g f p}$; Krox20Cre mice, we explored Krox20 lineage 
A
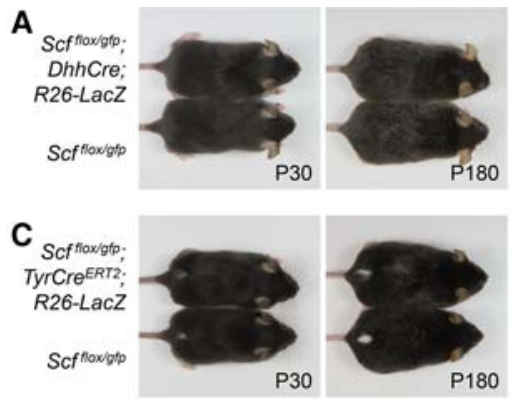

B

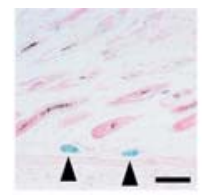

D
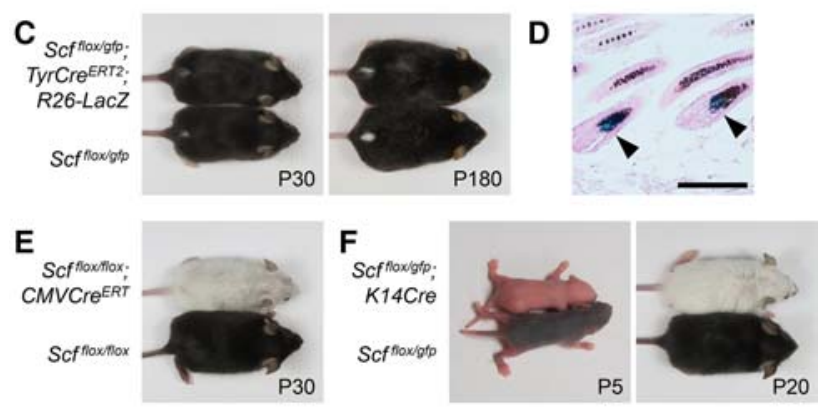

G

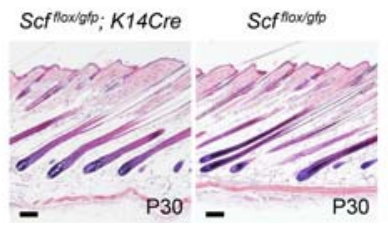

Scf floxigtp; K14Cre

Scf floxigto

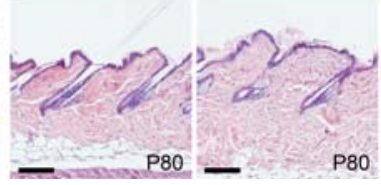

Figure 2. Hair pigmentation is dependent on SCF expression by epithelial keratinocytes. (A) Depletion of SCF in Schwann cells does not affect hair pigmentation. Scfflox/gfp; DhhCre mice exhibited normal hair pigmentation. $n=8$. (B) LacZ staining revealed that $D h h$ lineage cells were present in subcutaneous nerves (arrowheads). (C) Depletion of SCF in melanocytes does not affect hair pigmentation. Scfflox/gfp; TyrCre $e^{E R T 2}$ mice were induced by 4-hydroxytamoxifen at $\mathrm{P} 0$ and displayed normal hair pigmentation. $n=8$. (D) LacZ staining revealed that Tyr lineage cells were present in matrix melanocytes (arrowheads). (E) Scfflox/flox; $C M V C r e^{E R T}$ mice were induced by 4-hydroxytamoxifen as in $C$ to ablate SCF expression in all cells. These mice exhibited mostly hypopigmented hairs, and this lasted throughout their lives $(n=$ $5)$, validating an optimal 4-hydroxytamoxifen induction in $C$. (F) Depletion of SCF in epithelial cells completely abolishes hair pigmentation. Scf flox/gfp ; K14Cre mice had no hair pigmentation since birth, and this phenotype lasted throughout their lives. $n=8$. $(G)$ SCF expression in epithelial cells appears to regulate only hair pigmentation. In hematoxylin and eosin staining, $S c f^{f l o x / g f p}$; K14Cre mice displayed skin structure and hair cycling similar to those of littermate controls. Nuclei were stained with nuclear Fast Red in $B$ and $D$. Bar, $100 \mu \mathrm{m}$.

cells in skin at different HF developmental stages by crossing the Krox20Cre mice with R26-LacZ. Interestingly, we found that LacZ ${ }^{+}$cells were detected only as a small population of cells located at the infundibulum and bulge of the HF at PO. At P2, $\mathrm{LacZ}^{+}$cells occupied the entire upper portion of the HF. However, as the HF developed, they expanded in numbers along the outer root sheath and then colonized the matrix, beginning at about P6-P10. We analyzed at least three mice from each age and observed a consistent recombination pattern (Fig. 3A). At the final stage of differentiation, hair matrix keratinocytes undergo a unique type of programmed cell death that is marked by systematic destruction of the nucleus. These keratinized anucleate cells become enveloped by specialized and highly cross-linked membranes that eventually form the building blocks of the hair shaft. Strikingly, in P12 skin, we also observed LacZ activity within the hair shafts (Fig. 3A). This is direct evidence demonstrating that Krox20 lineage labels hair progenitor cells that give rise directly to the hair shafts. Importantly, considering the timing of the first appearance of $\mathrm{LacZ}^{+}$cells in the hair matrix, Krox20 lineage appears to mark only a subsequent wave of hair progenitors postnatally. This observation corresponds with the late onset of hair hypopigmentation in the Scflox/gfp; Krox20Cre mice (Fig. 1A; Supplemental Fig. S1A). It also revealed distinct developmental waves of hair shaft progenitor cells and, importantly, suggested that hair pigmentation is regulated by SCF expression in hair shaft progenitor cells.

We therefore examined SCF expression in Krox20 lineage cells by $S c f$ promoter-driven GFP $\left(S c f^{g f p}\right)$. Our data showed that SCF-expressing and Krox20 lineage cells were colocalized at the hair matrix at P6 (the time at which Krox20 lineage cells begin to colonize in the matrix) (Fig. 3B) and at the hair shaft at P12 (the time at which Krox20 lineage cells build the hair shaft) (Fig. 3C). These results support the model in which SCF expression in hair shaft progenitor cells controls hair pigmentation.

Our lineage tracing of Krox20 revealed a new identity of epithelial cells giving rise to the hair shaft (Fig. 3A). To determine the developmental origin of KROX20-expressing cells in the HFs, we generated K14Cre; R26-YFP mice to genetically label all K14 lineage epithelial keratinocytes early in development with YFP. We subsequently performed immunofluorescence staining against KROX20 and observed that KROX20 is expressed in a subpopulation of the of $K 14$ lineage cells in the HFs (Fig. 3D), indicating that that $\mathrm{HF} \mathrm{KROX} 20^{+}$cells are differentially derived from a $\mathrm{K}^{+} 4^{+}$keratinocyte lineage. The detection of KROX20 protein in the outer root sheath and matrix demonstrates that KROX20 is expressed actively during hair development. Taken together with the findings that $S c f$ depletion in Schwann cells does not cause hair hypopigmentation (Fig. 2A; Supplemental Fig. S2A,D), these results distinguish the origin of KROX $20^{+} \mathrm{HF}$ cells (epithelial derivative) from KROX20 ${ }^{+}$Schwann cells (neural crest derivative) during skin development.

Because hair shaft progenitor cells are differentiated from HF stem cells in the bulge and because their activation is associated with hair cycle, we therefore tested the hypothesis that depletion of SCF in HF stem cells will result in hair hypopigmentation in a hair cycle-dependent manner. To address this hypothesis, we used the inducible K14Cre ${ }^{E R T}$ mouse line (Vasioukhin et al. 1999) to examine the effects of $S c f$ gene ablation in HF stem cells. The inductions of SCF ablation in Scflox/gfp ; K14Cre ERT mice were performed at different HF growth stages. Scfflox/gfp; K14Cre ${ }^{E R T}$ mice with induction of SCF ablation at P0 (in anagen, when some hair shaft progenitor cells have already formed) showed normal hair pigmentation initially; however, their coat color turned gray after subsequent anagen (Supplemental Fig. S3A), phenocopying the Scflox/gfp; Krox20Cre mice. On the other hand, Scfllox/gfp; K14Cre $e^{E R T}$ mice with induction of SCF loss and depilation together at P90 (in telogen, when hair shaft progenitor cells have not 


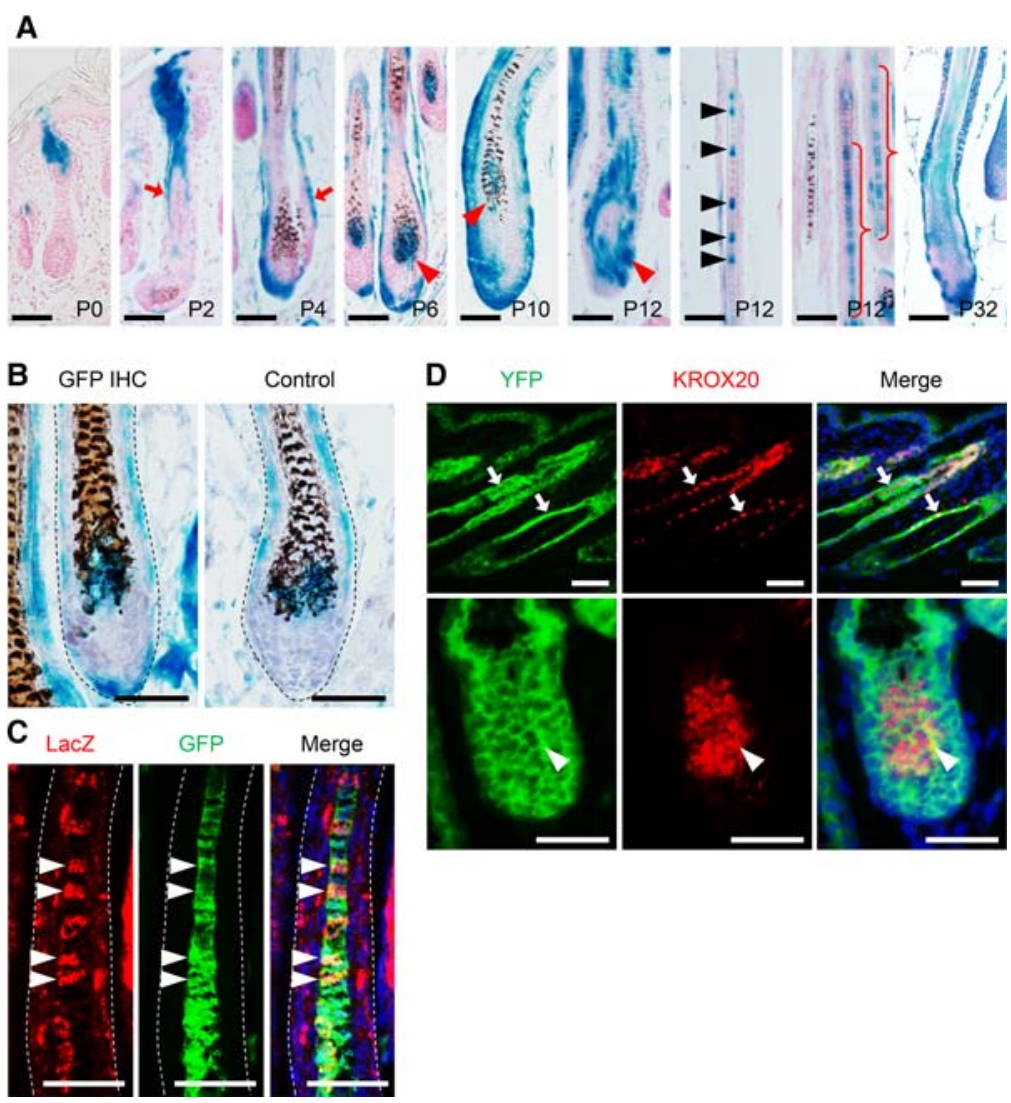

Figure 3. Dynamic localization of Krox20 lineage cells during HF morphogenesis. (A) Lineage tracing of Krox 20 by LacZ in the skin of postnatal Scflox/gfp; Krox20Cre; R26-LacZ mice revealed a dynamic localization of Krox20 lineage cells during HF morphogenesis. At P0, LacZ was detected only in the infundibulum and bulge of HFs. They then underwent an expansion along outer root sheath (arrows). Beginning around P6-P10, LacZ was also detected in the hair matrix (red arrowheads). Importantly, at P12, LacZ was detected in the hair shaft (black arrowheads and curly brackets), demonstrating that Krox20 lineage traced the matrix progenitor cells giving rise to hair shafts. Note that the P12 matrix and hair shaft are absent of pigment. Krox20 lineage also marks the same population of cells in the subsequent hair cycle at P32. (B) In P6 Scflox/gfp; Krox20Cre; R26-LacZ HFs, Krox20 lineage cells (marked by LacZ) were colocalized with SCF-expressing cells (marked by GFP) in the hair matrix. $(C)$ In P12 Scflox $/ g f p ;$ Krox20Cre; R26-LacZ HFs, Krox20 lineage cells (marked by LacZ) were colocalized with SCF-expressing cells (marked by GFP) in the hair shaft (arrowheads). (D) In P12 K14Cre; R26-YFP HFs, KROX20 is detected in the K14 lineage epithelial cells in the outer root sheath (arrows) and the hair matrix (arrowheads). Nuclei were stained with nuclear Fast Red in $A$, hematoxylin in $B$, and DAPI in $C$ and $D$. Bar, $50 \mu \mathrm{m}$.

yet formed) showed an immediate depigmented coat in the newly regenerated hairs (Supplemental Fig. S3B). These results revealed that induction of SCF loss in HF stem cells at different HF developmental stages can result in different patterns of hair color changes. Ablation of SCF in HF stem cells at telogen depleted SCF in all subsequent differentiating HF cells; therefore, all hair shaft progenitor cells acquired SCF ablation and gave rise to hypopigmented hairs immediately. In contrast, induction of SCF loss in HF stem cells at anagen depleted SCF only in newly differentiated hair shaft progenitor cells but not those differentiated before the induction, explaining the normally pigmented hairs followed by hypopigmented hairs (Supplemental Fig. S3E). These results supported our conclusion that the active expression of SCF in hair shaft progenitor cells is critical for hair pigmentation.

\section{The hair matrix is the SCF-dependent niche for hair pigmentation}

In Scflox/gfp; K14Cre mice, the complete loss of hair pigmentation is caused by Scf deletion in K14 lineage cells. We therefore hypothesized that this depigmentation could be rescued by ectopic $S c f$ expression under a K14 promoter. To test this hypothesis, we used a mouse transgene with a K14 promoter-driven membrane-bound form of Scf (K14$S c f)$, which produces a dominant phenotype of epidermal hyperpigmentation (Kunisada et al. 1998a). Given that a mouse mutant expressing only a soluble form of SCF $\left(S 1^{d} / S 1^{d}\right)$ has no skin or hair pigmentation (Copeland et al. 1990; Brannan et al. 1991), we reasoned that hair pigmentation is dependent on membrane-bound SCF and thus that the K14-Scf transgene should be a suitable tool to address the requirement of SCF for hair pigmentation.

Surprisingly, the K14-Scf; Scflox/gfp; K14Cre mice displayed white hair with dark skin (Fig. 4A,B), indicating that even though $S c f$ is expressed under a K14 promoter, K14-Scf was unable to rescue the hair depigmentation in Scf flox/gfp ; K14Cre mice. Likewise, we observed that K14$S c f$ did not rescue the hair-graying progress in $S c f^{f l o x / g f p}$; Krox20Cre mice. The K14-Scf; Scf flox/gfp ; Krox20Cre mice underwent hair graying identical to that of $S c f^{f l o x / g f p}$; Krox20Cre control mice (Fig. 4C), although the K14-Scf transgene appeared to remain active over time (Fig. 4D). These findings are similar to earlier experiments in which the K14-Scf transgene was unable to rescue hair hypopigmentation in $S 1^{d} / S 1^{d}$ mice (Yoshida et al. 2001) or KIT-neutralizing antibody ACK2-treated mice (Nishimura et al. 2002).

To explore the underlying mechanism by which ectopic expression of K14-Scf failed to rescue the Scf loss-induced hair hypopigmentation, we reasoned that perhaps the $\mathrm{K} 14$ promoter activity is turned off in the $\mathrm{KROX} 20^{+}$hair shaft progenitor cells in the matrix, and therefore the lack of SCF expression had regulated hair pigmentation. To address this question, we lineage-traced the cells with "Scf ablation" by R26-YFP (as a marker for K14Cre lineage) 

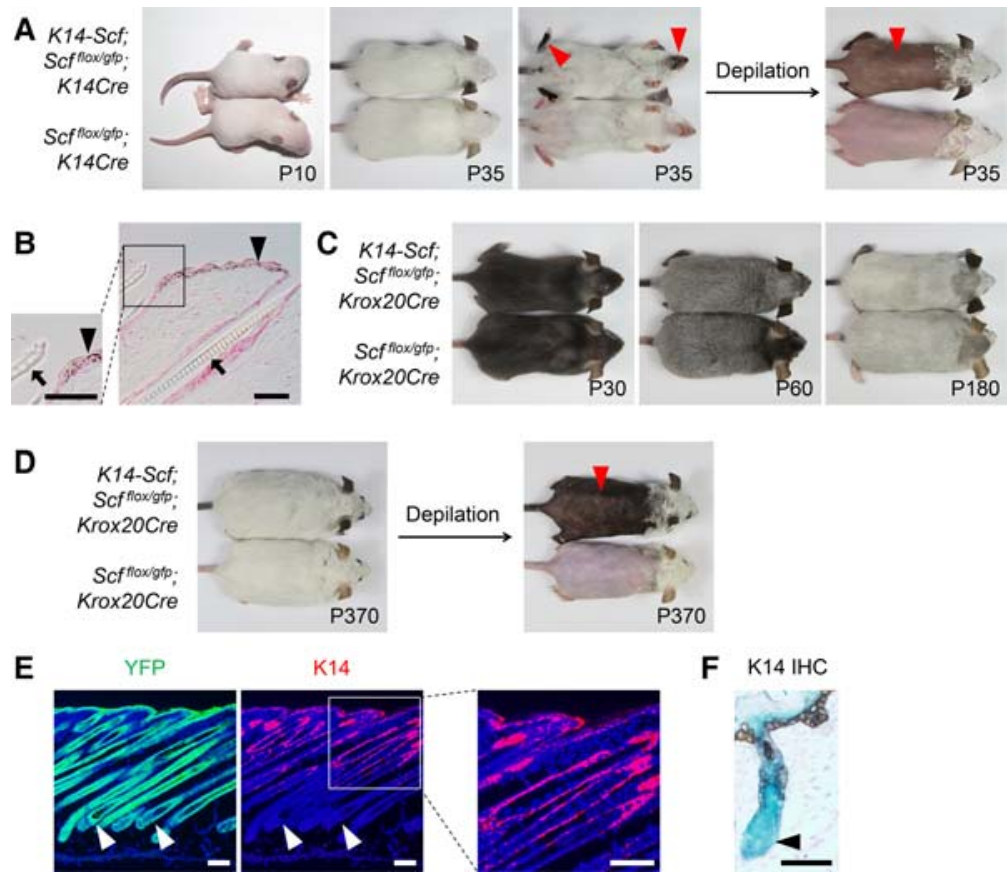

and identified the cells with "Scf reconstitution" by K14 immunostaining (as a marker for K14 promoter) in the skin from K14Cre; R26-YFP mice. Intriguingly, YFP was detected in the interfollicular epithelium and the entire HF (except dermal papillae), whereas K14 was detected only in the interfollicular epithelium and only the top portions of anagen $\mathrm{HF}$ (Fig. 4E); similar results were obtained from K14Cre; R26-LacZ mice (Fig. 4F). This expression pattern matches previous studies on $\mathrm{K} 14 \mathrm{Cre}$ lineage tracing (Huelsken et al. 2001) and K14 expression (Coulombe et al. 1989). Most importantly, these data demonstrate that hair pigmentation is tightly dependent on SCF from the Krox20 lineage cells in the hair matrix of HFs that are differentiated from K14 lineage but no longer express K14.

To better characterize the expression of SCF during HF development, we then took advantage of another marker, GFP, to locate the SCF-expressing cells by using the $S c f^{g f p}$ mice. We found that $\mathrm{GFP}^{+}$cells are predominantly localized in the upper hair matrix and hair shaft (but not the bulge or outer root sheath area) throughout the anagen stage (Fig. 5A), pointing to the hair shaft progenitor cells as a unique cell type expressing SCF during the HF growth stage. This observation was supported by the inclusion of melanin pigment (Fig. 5B) and the expression of P-cadherin (Fig. 5C) in these SCF-expressing cells. P-cadherin is an epithelial cell-cell adhesion molecule and, in HFs, marks the outer root sheath, inner matrix, and hair shaft (Samuelov et al. 2012). As the hair matrix is also colonized by melanocytes, we therefore determined the location of mature melanocytes by immunostaining of dopachrome tautomerase (DCT). DCT is an enzyme participating in melanin biogenesis and, in HFs, marks mature melanocytes in the hair
Figure 4. The hair matrix is the SCF-dependent niche for hair pigmentation. (A) Ectopic SCF expression by K14 promoter-driven $S c f(K 14-S c f)$ does not rescue hair hypopigmentation. K14-Scf; Scfllox/gtp; K14Cre mice displayed white hairs and dark skin (arrowheads). $n=8$. (B) Skin histology in K14-Scf; $S c f^{f l o x / g f p}$; K14Cre mice revealed epidermal hyperpigmentation (arrowheads) and unpigmented hair shafts (arrows). (C) K14-Scf does not rescue hair graying. K14-Scf; Scf flox/gfp; Krox20Cre mice underwent hair graying similar to Krox20Cre; $S c f^{f l o x / g f p}$ controls. $n=$ 8. (D) K14-Scf transgene remained active along aging, as indicated by the permanent skin hyperpigmentation (arrowhead) in 1-yr-old mice. $n=3$. $(E)$ Hair matrix cells differentiate from K14 lineage cells but no longer express K14. K14 immunostaining in K14Cre; R26-YFP skin from P10 mice revealed that K14-expressing cells are restricted in the interfollicular epithelium and the top portion of HFs. Importantly, HF matrix cells (arrowheads) do not express K14, although they differentiated from K14 lineage cells (marked by YFP). Nuclei were stained with DAPI. (F) Using a similar approach as in $D$, in P0 skin, K14 immunohistochemical staining marked the interfollicular epithelium and the top portion of HFs but not HF matrix cells (arrowhead), whereas K14 lineage (marked by LacZ) traced to the entire skin and HF epithelium. Bars: $B, E, 50 \mu \mathrm{m} ; D, 100 \mu \mathrm{m}$. matrix predominantly and a small number of melanocyte stem cells in the bulge (Nishimura et al. 2005). $\mathrm{DCT}^{+}$melanocytes are tightly adjacent to the SCF-expressing cells in the matrix (Fig. 5D); this result is in agreement with the identification of matrix SCF-expressing cells as the hair shaft progenitor cells. Taken together, we concluded that hair pigmentation is controlled exclusively by SCF on hair shaft progenitor cells, which regulates melanocytes in the HF matrix in a non-cell-autonomous fashion.

\section{SCF in the matrix is crucial for the maintenance of mature melanocytes}

We showed that depletion of SCF in the hair shaft progenitor cells results in loss of hair pigmentation. In addition, melanocytes are the specialized melanin-producing cells as well as the predominant KIT-expressing cells in the HF (Lin and Fisher 2007). Therefore, melanocytes mediate SCF signaling to hair pigmentation, and SCF is necessary for melanocytic activity and hair pigmentation. Thus, we next addressed the fate of follicular melanocytes in response to the loss of SCF in the hair shaft progenitor cells.

The Scflox/gfp; Krox20Cre mice began to lose hair pigmentation at P11-P13 due to SCF loss in their hair shaft progenitor cells (Fig. 1D-F). We took advantage of this model to address the fate of melanocytes during SCF loss. As hair shaft progenitor cells are tightly adjacent to melanogenic melanocytes in the upper HF matrix (Fig. $5 \mathrm{D}$ ), we thus hypothesized these mature melanocytes to be the first affected cells. Indeed, DCT immunostaining revealed a significant loss of $\mathrm{DCT}^{+}$differentiated mature melanocytes in the Scfflox/gfp; Krox20Cre mouse HF at 


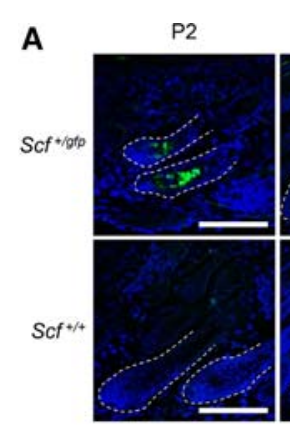

C

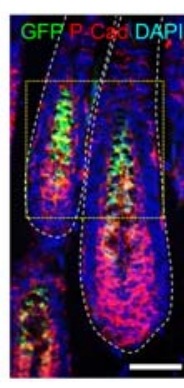

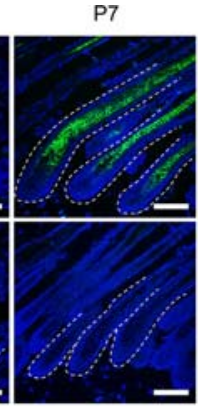

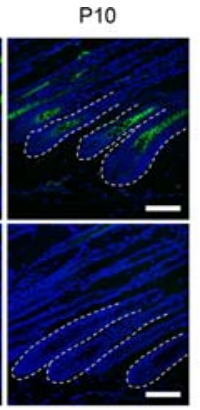

B

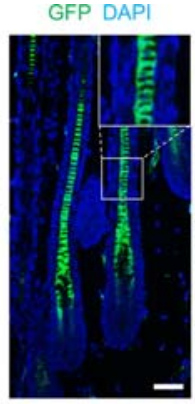

D
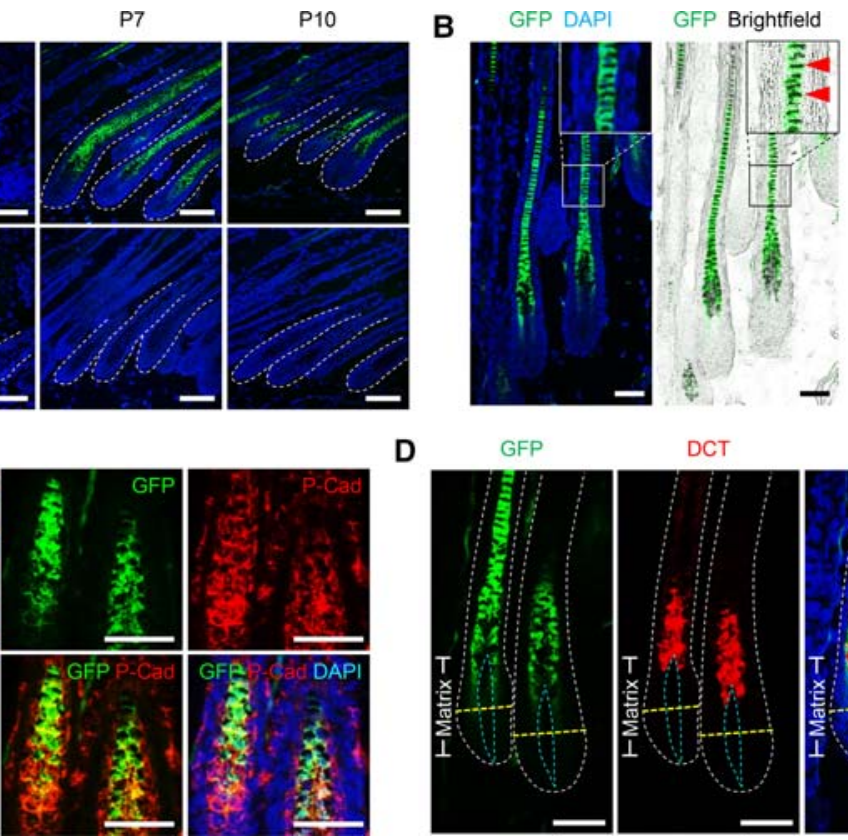

Figure 5. SCF is expressed in hair shaft progenitor cells. $(A)$ Scf promoter-driven GFP $\left(S c f^{g f p}\right)$ showed that SCF is expressed in the upper HF matrix and hair shaft throughout anagen. $(B)$ SCF is expressed in melanin-containing cells (arrowheads) in the HF in P10 $S c f^{+} / g f p$ skin. $(C)$ SCF is expressed in a subpopulation of P-cadherin ${ }^{+} \mathrm{HF}$ matrix cells and the hair shaft in P9 Scf $f^{+/ g f p}$ skin. $(D) \mathrm{DCT} \mathrm{T}^{+}$melanocytes are tightly adjacent to SCF-expressing cells in the upper HF matrix in P10 Scf $f^{+/ g f p}$ skin. (Yellow dashed line) Line of Auber (an imaginary line drawn across the widest region of the hair bulb); (blue dashed line) dermal papilla. Nuclei were stained with DAPI. Bars: $A, 100 \mu \mathrm{m} ; B-D, 50 \mu \mathrm{m}$

P10 $(P<0.05)$ and P11 $(P<0.0001)$ (Fig. 6A-C). This result demonstrated a critical role of SCF in the maintenance of mature melanocytes.

Furthermore, we explored the fate of $\mathrm{DCT}^{+}$melanocytes in another mouse model: Scf flox/gfp; K14Cre. These mice had a complete loss of hair pigmentation throughout their lifetimes (Fig. 2F). Therefore, it was not surprising that $\mathrm{DCT}^{+}$melanocytes were not detected in their hair matrices (Fig. 6D). The HF melanocytes have been characterized previously to express KIT, which is the receptor for SCF (Lennartsson and Ronnstrand 2012). Melanocytes in the upper and lower follicular matrix compartments can be separated by the Line of Auber (an imaginary line drawn across the widest region of the hair bulb) (Peters et al. 2002). Melanocytes in the lower matrix are relatively undifferentiated and nonmelanogenic. However, differentiated mature melanocytes reside in the upper HF matrix and produce melanin. We further characterized the extent to which SCF can affect these two melanocyte populations by utilization of this other melanocyte marker: KIT. KIT ${ }^{+}$melanocytes were present in both lower and upper HF matrices in the control skin. However, in the skin from Scflox/gfp; K14Cre mice, $\mathrm{KIT}^{+}$melanocytes were detected only in the lower matrix but were completely absent in the upper HF matrix (Fig. 6E). This finding demonstratesthat loss of SCF in the hair shaft progenitor cells influences only the mature melanocytes, highlighting the upper HF matrix as a critical niche where non-cell-autonomous SCF/KIT signaling regulates hair pigmentation. It also points to the critical role of follicular epithelial SCF in controlling the fate of melanocytes in their final maturation without affecting their previous differentiation and migration.

\section{HF Krox20 lineage cells are critical for hair development}

Based on our work, we concluded that the transcription factor KROX20 marks a lineage of resident hair shaft progenitor cells in the follicular matrix. Therefore, we hypothesized that Krox20 lineage cells are indispensible for hair growth. To test this hypothesis, we generated a doxycycline-inducible mouse model (Krox20Cre; R26rtTA; tetO-DTA) to deplete Krox20 lineage cells in vivo. The R26-rtTA expresses reverse tetracycline-controlled transactivator (rtTA) (Belteki et al. 2005) in the Krox20 lineage cells. The tetO-DTA expresses diphtheria toxin A (DTA) (Lee et al. 1998) to eliminate cells with rtTA expression (Krox20 lineage cells in this case) upon doxycycline induction (Fig. 7A). We used this model to examine the effects of Krox20 lineage cell depletion during the second anagen phase (starting at about P23-P24). Mice were fed with doxycycline water starting at P20. We observed signs of hair loss (rough coat) starting at starting P40, and they had significant hair loss by P50 (Fig. 7B). As expected, these mice also displayed weak muscle tone (data not shown), which is likely associated with the peripheral nerve demyelination caused by $\mathrm{KROX}^{2} 0^{+}$cell depletion (Decker et al. 2006). To determine whether this hair loss, induced by Krox20 lineage cell depletion, was caused by impaired hair growth or increased hair 

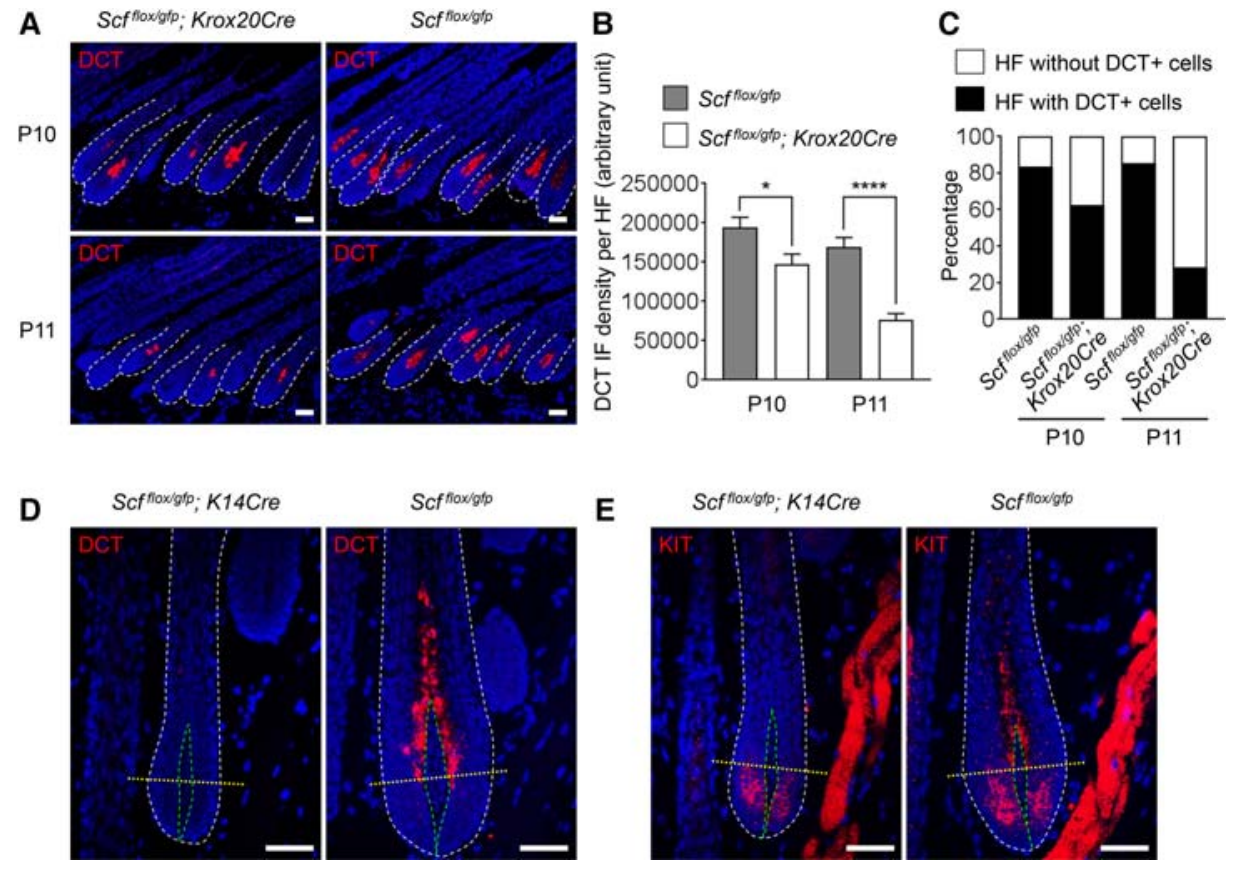

Figure 6. SCF is required for the maintenance of mature melanocytes. $(A)$ Loss of matrix DCT ${ }^{+}$melanocytes in Scflox/gfp; Krox20Cre mice. DCT immunostaining revealed that the number of matrix $\mathrm{DCT}^{+}$melanocytes decreased rapidly right before hair lost pigmentation in Scflox/gfp; Krox20Cre mice. (B) Quantification and statistical analysis of $A$ revealed a significant and rapid decrease of matrix DCT staining intensity in Scflox $/ g f p$; Krox20Cre mice during P10-P11. Data are mean \pm SEM from $n \geq 53$ HFs in each group. $\left(^{* * * *}\right) P<0.0001 ;\left({ }^{*}\right) P<$ 0.05. (C) Quantification and statistical analysis of $A$ revealed increased numbers of hair matrices without DCT in Scflox/gfp; Krox20Cre mice during P10-P11. $n \geq 53$ HFs per group. $(D)$ DCT immunostaining revealed that $S c f^{f l o x} / g f p ; ~ K 14 C r e$ mouse HFs were completely absent of matrix DCT ${ }^{+}$mature melanocytes. (E) KIT immunostaining revealed that Scflox/gfp; K14Cre mouse HFs lost KIT ${ }^{+}$melanocytes above the Line of Auber (differentiated mature melanocytes); however, $\mathrm{KIT}^{+}$melanocytes still detected below the Line of Auber. Nuclei were stained with DAPI. (Yellow dashed line) Line of Auber; (green dashed line) dermal papillae. Bar, $50 \mu \mathrm{m}$.

shedding, we examined the effects of depilation on new hair growth. Mice were depilated to induce new hair growth at P20. At the same time, they were started on doxycycline water to deplete Krox20 lineage cells in vivo. Within $15 \mathrm{~d}$, control mice (R26-rtTA; tetO-DTA) regrew their entire hair coat. On the other hand, Krox20Cre; R26-rtTA; tetO-DTA mice had a complete arrest of new hair generation (Fig. $7 \mathrm{C}$ ), demonstrating the critical role of Krox20 lineage cells in hair development.

To characterize further the role of Krox20 lineage cells in HF development, we examined the skin of Krox20Cre; R26-rtTA; tetO-DTA mice after doxycycline treatment between P20 and P50 to assess the impact of Krox20 lineage cell depletion on hair regeneration. We found that Krox20 lineage cell-depleted HFs were arrested at anagen (Fig. 7D), whereas the control HFs completed the anagen phase and rested at telogen (Fig. 7F). Importantly, in contrast to normal anagen HFs, Krox20 lineage cell-depleted HFs had shrunken hair bulbs, which were located near to where the hair shaft progenitor cells had resided previously (Fig. 7E). This atypical anagen phase, with missing stereotypic bulb structure (the reservoir of matrix cells), explained their inability to grow new hair. We also noticed that the Krox20 lineage cell-depleted skin exhibited ectopic melanin deposition around the HFs (Fig. 7G); this is likely contributed by the death of Krox20 lineage cells after obtaining the melanin from melanocytes, as we started the doxycycline treatment on the same day of depilation, and therefore it will take some time after the doxycycline treatment for the diphtheria toxin A to delete the Krox20 lineage cells. The appropriateness of this system was validated by faithful depletion of KROX20 cells in vivo after doxycycline induction (Fig. $7 \mathrm{H}$ ). Taken together, these analyses confirm the critical role of Krox20 lineage cells in hair development as the cells that produce hair directly.

\section{Discussion}

We identified that the transcription factor KROX20 marks a cell lineage differentiating toward the hair shaft and that SCF in these hair shaft progenitor cells acts as a critical intrinsic rheostat of hair pigmentation by managing mature melanocyte in the upper HF matrix. Ablation of $S c f$ in Krox20 lineage cells consequently leads to a complete absence of hair pigmentation, showing an indispensible noncell-autonomous SCF contribution to melanocytes and that Krox20 lineage cells are the main source of SCF for follicular mature melanocytes to produce hair pigment. The completion of hair regeneration is dependent on the presence of HF Krox20 lineage cells as the cells giving rise directly to hair shafts (Fig. 7I). 


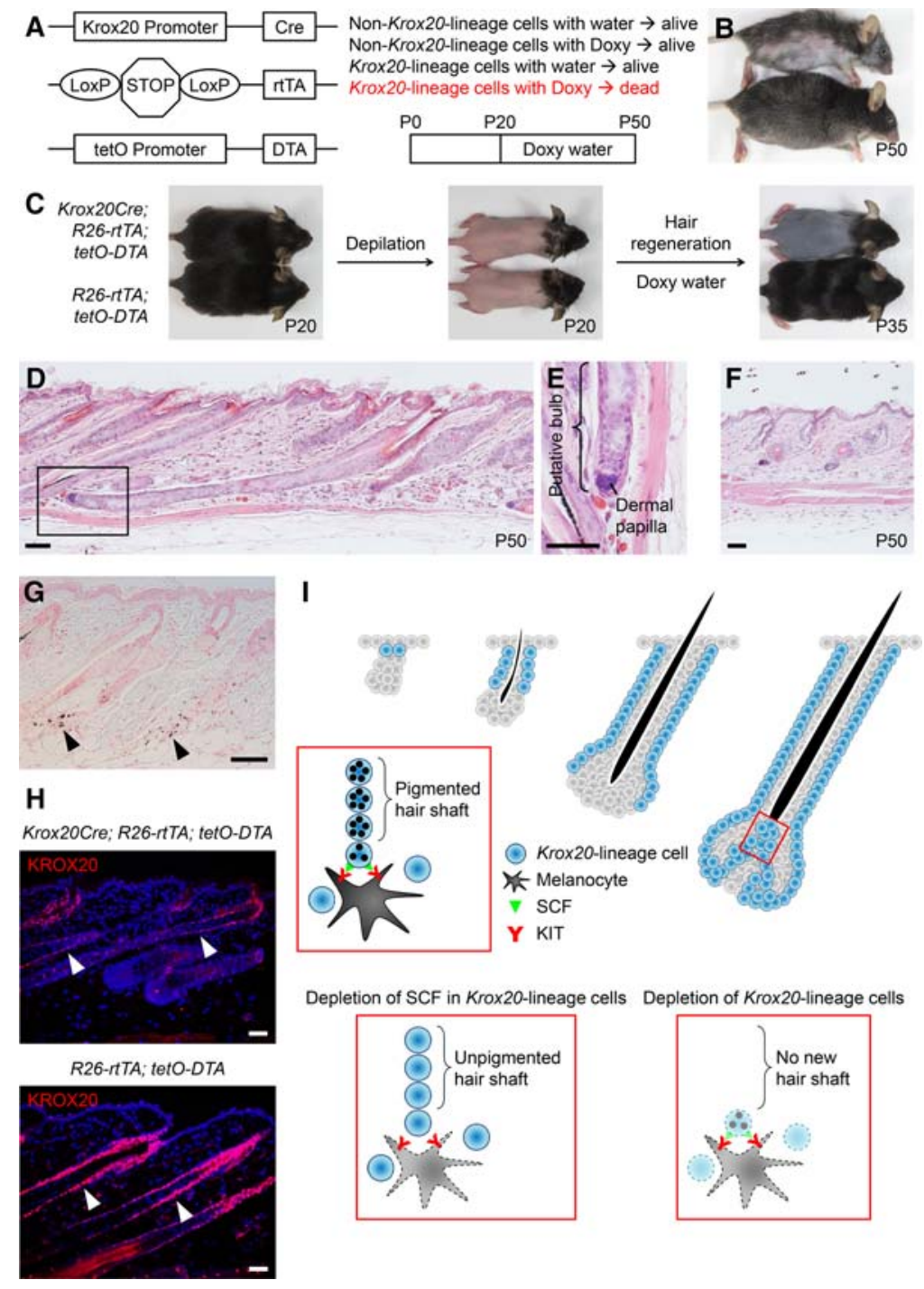

Figure 7. HF Krox20 lineage cells are critical for hair development. (A) Schematic illustration of the doxycycline-inducible mouse model to deplete Krox20 lineage cells in vivo. Krox20Cre; R26-rtTA; tetO-DTA allows the killing of Krox20 lineage cells by DTA in mice upon doxycycline treatment. (B) Krox20Cre; R26-rtTA; tetO-DTA (top) and littermate control (bottom) mice were treated with doxycycline from P20 to P50. Remarkable hair loss was observed in Krox20Cre; R26-rtTA; tetO-DTA mice at P50. $n=8$. (C) Krox20Cre; R26-rtTA; tetO-DTA mice were depilated at P20 followed by doxycycline treatment from P20 to P35; notably impaired new hair growth was observed. $n=3$. $(D)$ The HFs in P50 Krox20Cre; R26rtTA; tetO-DTA mice were arrested in anagen with an atypical HF structure composed of elongated HFs and shrunken hair bulbs. (E) A close-up view of $D$ to emphasize the aberrant hair bulb structure. $(F)$ The HFs in P50 R26-rtTA; tetO-DTA control mice were rested in telogen. $(G)$ Ectopic melanin deposition (arrowheads) around HFs was noticed in Krox20Cre; R26-rtTA; tetO-DTA mice. (H) KROX20 immunostaining confirmed a substantial reduction of KROX $20^{+}$cells in Krox20Cre; R26-rtTA; tetO-DTA mice after doxycycline treatment. Nuclei were stained with DAPI. (I) Schematic illustration of the roles of SCF and Krox20 lineage cells in hair pigmentation and development. Lineage tracing of Krox20 lineage cells revealed a dynamic expansion toward the direction of hair-producing cells during HF morphogenesis in the upper HF matrix (red box). Hair progenitor cells sustain differentiated melanocytes through non-cell-autonomous SCF/KIT signaling. Depletion of SCF in hair progenitor cells results in loss of hair pigmentation. Depletion of Krox20 lineage cells, the cells that differentiate into hair-producing cells, results in impaired hair regeneration. Bar, 50 $\mu \mathrm{m}$.
SCF production in keratinocytes appears solely to regulate the generation of hair pigmentation by melanocytes because no skin or hair developmental defect was observed in the Scflox $/ g f p$; Krox20Cre or Scfflox/gfp; K14Cre mice (Figs. 1D, 2G). The critical role of SCF/KIT signaling in hair pigmentation has long been recognized (Copeland et al. 1990; Reith et al. 1990; Okura et al. 1995); however, this is the first report to identify Krox20 lineage hair shaft progenitor cells definitively as the source of SCF to control this process. This discovery could lead to additional studies to characterize their contributions to other signaling events that are critical for melanocyte development, including the effects of Notch (Schouwey et al. 2007), TGF $\beta$ (Nishimura et al. 2010), and $\beta$-catenin (Rabbani et al. 2011). During the development of melanocytes, the neural crest stem cells generate melanoblasts that subsequently become melanocyte stem cells. Although melanocyte stem cells in the bulge do not require SCF, their differentiation into mature melanocytes is SCF-dependent (Nishimura et al. 2002), consistent with our finding that loss of SCF in hair shaft progenitor cells targets only the mature melanocytes in the matrix and not the undifferentiated melanocyte precursors.

While dissecting the hair-graying phenotype of Scf flox/gfp ; Krox20Cre mice, we surprisingly discovered that this hair color change is associated with distinct stages in the cells committed to hair production. Krox20 lineage marks the hair shaft progenitor cells only after P6-P10 (Fig. 3A), which demonstrates the presence of a second wave of hair shaft progenitor cells and explains the late onset of hair hypopigmentation and eventual complete depigmentation in Scflox/gfp; Krox20Cre mice. Interestingly, late onset of the hair hypopigmentation phenotype has also been observed in other genetically modified mice. $\mathrm{Bcl}^{-/-}$mice (Veis et al. 1993) and Notch1 $1^{\text {flox } /+}$; Notch2 flox/flox ; TyrCre mice (Schouwey et al. 2007) exhibit hair graying that is similar to that of the $S c f^{\text {flox/gfp }}$; Krox20Cre mice. Loss of BCL2-dependent melanocyte stem cells beginning from P8 has been identified to cause 
the hair graying in $\mathrm{Bcl}^{-/-}$mice (McGill et al. 2002; Nishimura et al. 2005). On the other hand, $\beta$-cat ${ }^{\text {flox }_{-}-}$; K14Cre mice (Huelsken et al. 2001) display late-onset hair loss. They develop hairs after birth, but most of these hairs are lost as they grow into adulthood. Taken together, these late-onset phenotypes might be related to our two-wave hair growth model. Furthermore, this model could shed light on the classification of embryonic and adult stem cells that are committed to the same type of tissue generation.

KROX20 is best known as a transcription factor for Schwann cells during differentiation from promyelinating to myelinating states (Topilko et al. 1994), which takes place primarily during early postnatal development (Zorick et al. 1999). This phenomenon is similar to the expansion of HF Krox20 lineage cells during hair morphogenesis (Fig. 3A). A recent study has revealed that peripheral nerve KROX20 induction is regulated by the Lin28/Let-7 axis (Gokbuget et al. 2015). Lin28 is a conserved RNA-binding protein that is expressed highly in embryonic stem cells. It is also diminished sharply after birth; this change results in the induction of Let-7 microRNA (Shyh-Chang and Daley 2013). Interestingly, Lin28a transgenic mice exhibit a thickened hair coat due to prolonged anagen (Shyh-Chang et al. 2013). These results suggest that KROX20 could be a downstream regulator for Lin28/Let-7-mediated perinatal development in both nerves and skin.

The bone morphogenetic protein (BMP) and Wnt/ $\beta$-catenin signaling plays a central role in epidermal homeostasis and HF development (Blanpain and Fuchs 2009; Solanas and Benitah 2013; Plikus and Chuong 2014). Mice with K5 promoter-driven BMP antagonist noggin (K5-noggin) are characterized by enlarged anagen HFs with thickened hair shafts; this feature is associated with hyperproliferative hair matrix cells with a sixfold decrease in Krox20 expression (Sharov et al. 2006). Similarly, K14-noggin mice have a faster response to hair regeneration (Plikus et al. 2008). Moreover, Wnt activation leads to up-regulation of KROX20, and this induction can be synergized by BMP inhibition with noggin (SaintJeannet et al. 1997; Baker et al. 1999|. Taken together with our findings, the functional prediction for KROX20 in HF development could be a downstream effector of Wnt $/ \beta$-catenin and BMP signaling, thereby directing HF stem cell differentiation.

In conclusion, this study delineates the origin of SCF expression in the hair matrix progenitors as a niche for follicular mature melanocytes and that their SCF is indispensible for hair pigmentation. In addition, SCF expression in the matrix identifies immediate antecedents of hair shaft structural cells, and transcription factor KROX20 marks a sublineage of epithelial cells differentiating toward this hair shaft progenitor cells. Future studies to reconstitute SCF in the matrix niche will be interesting and will address whether hair hypopigmentation could be reversible. Furthermore, genetic ablation of Krox20 and global profiling of KROX20 transcriptional targets will help to elucidate its biological roles in epidermal differentiation and HF development.
Materials and methods

Mice

Animal care and experiments were approved by the Institutional Animal Care and Use Committee at University of Texas Southwestern Medical Center. $S c f^{f l o x}$ and $S c f^{g f p}$ were generated in a previous report (Ding et al. 2012). K14Cre (Dassule et al. 2000),

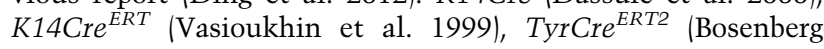
et al. 2006), R26-rtTA (Belteki et al. 2005), and tetO-DTA (Lee et al. 1998) mice were purchased from the Jackson Laboratory. K14-Scf (Kunisada et al. 1998a) was kindly provided by Dr. John Harris (University of Massachusetts Medical School). Krox20Cre (Voiculescu et al. 2000), DhhCre (Skucas et al. 2013), PLPCre ${ }^{E R T 2}$ (Leone et al. 2003), CMVCre $e^{E R T}$ (Hayashi and McMahon 2002), R26-LacZ, and R26-YFP were described previously (Le et al. 2009; Chen et al. 2014).

Tamoxifen and 4-hydroxytamoxifen induction

Tamoxifen or 4-hydroxytamoxifen (Sigma-Aldrich) was administered to mice to induce $C r e^{E R T}$ or Cre $e^{E R T 2}$ expression. For induction in a newborn mouse, a single-dose treatment of $40 \mu \mathrm{g}$ of 4 hydroxytamoxifen was injected subcutaneously. For induction in adult mice, $3 \mathrm{mg}$ of tamoxifen was oral-gavaged daily for five consecutive days.

\section{Doxycycline induction}

For the induction of tetO-DTA, mice were fed with water containing $2 \mathrm{mg} / \mathrm{mL}$ doxycycline (Sigma-Aldrich) and 5\% sucrose.

Mouse hair depilation

Mice were anesthetized by intraperitoneal injection of $100 \mu \mathrm{L}$ /for a 25 -g mouse) of a mixture of $30 \mathrm{mg} / \mathrm{mL}$ ketamine and $4 \mathrm{mg} / \mathrm{mL}$ xylazine solution. Mouse hair was trimmed by an electrical clipper. Depilatory cream (Nair) was applied gently on the area to be depilated and then wiped off with water-moistened gauzes to remove the hair.

\section{Histology analysis}

For histology analysis, skin tissue was harvested and fixed in $10 \%$ formalin overnight followed by paraffin embedding. The tissue was then sectioned at 5 - $\mu \mathrm{m}$ thickness. Hematoxylin and eosin staining was performed according to the manufacturer's protocol (StatLab).

LacZ staining

For LacZ staining, mice were anesthetized by intraperitoneal injection of ketamine and xylazine as described above. Mice were then subjected to total body perfusion with $4 \%$ paraformaldehyde. Skin was harvested and fixed in $4 \%$ paraformaldehyde for 30 min followed by PBS rinses. LacZ staining was performed in 4-chloro-5-bromo-3-indolyl- $\beta$-galactoside (X-gal) solution (1 mg/ $\mathrm{mL} \mathrm{X-gal,} 4 \mathrm{mM}$ potassium ferrocyanide, $4 \mathrm{mM}$ potassium ferricyanide, $2 \mathrm{mM}$ magnesium chloride in PBS) overnight at $37^{\circ} \mathrm{C}$. X-gal-stained tissue was fixed in $10 \%$ formalin overnight and then subjected to paraffin embedding and tissue sectioning. Nuclei were counterstained with nuclear Fast Red.

Fontana-Masson staining

Paraffin-embedded tissue sections were deparaffinized and rehydrated. Melanin staining was performed by microwaving tissue 
sections in ammoniacal silver working solution for $2 \mathrm{~min}$. The ammoniacal silver stock solution was prepared by adding ammonium hydroxide to $10 \%$ silver nitrate until the solution precipitated and cleared again; the working solution was freshly prepared by mixing the stock solution with water at $1: 3$ ratio followed by filtering. Slides were then incubated with $0.1 \%$ gold chloride for $10 \mathrm{~min}$ and $5 \%$ sodium thiosulfate for $5 \mathrm{~min}$ with water rinses between each step. Nuclei were counterstained with nuclear Fast Red.

\section{Immunostaining}

For immunostaining, frozen sections or paraffin sections after deparaffinization, rehydration, and antigen retrieval were used. The primary antibodies used in this study were P-cadherin (R\&D Systems, AF761), DCT (PEP8h; gift from Dr. Vincent Hearing, National Institutes of Health) (Virador et al. 2001), K14 (biotin-labeled, Thermo, clone LL002), LacZ (Abcam, ab9361), GFP/ YFP (Aves, 1020), Krox20 (Covance, PRB-236P), and KIT (Cell Signaling, 3074). For immunofluorescent staining, the primary antibodies were detected by secondary antibodies or streptavidin conjugated with Cy3 or Alexa fluor 488 (Jackson ImmunoResearch), and nuclei were counterstained with DAPI (Vector Laboratories). For immunohistochemical staining, the primary antibodies were detected by secondary antibodies or streptavidin conjugated with 3,3' diaminobenzidine (Vector Laboratories).

\section{Statistical analysis}

Data statistical analyses were performed by unpaired two-tailed Student's $t$-test (Prism7, GraphPad). Data are mean \pm SEM. Significant differences were noted by asterisks $(\mathrm{P}<0.05$ [*], $\mathrm{P}<$ $0.01[* *], \mathrm{P}<0.001\left[{ }^{* * *}\right]$, and $\left.\mathrm{P}<0.0001\left[{ }^{* * * *}\right]\right)$.

\section{Densitometry analysis}

The quantification of HF melanin density and DCT immunofluorescence staining intensity was performed with ImageJ software (National Institutes of Health) in arbitrary units.

\section{Acknowledgments}

We thank all members of the Le laboratory and K.B. Yancey for helpful suggestions and discussions, Y. Wang for technical assistance, and P.R. Bergstresser for critical review of the manuscript. We also thank J.E. Harris and V.J. Hearing for sharing K14-Scf mice and the anti-DCT antibody, respectively. C.-P.L. is a recipient of the Career Development Award from the Dermatology Foundation and the Young Investigator Award from the Children's Tumor Foundation. L.Q.L. holds a Career Award for Medical Scientists from the Burroughs Wellcome Fund and the Thomas L. Shield M.D. Professorship in Dermatology. S.J.M. is a Howard Hughes Medical Institute Investigator, the Mary McDermott Cook Chair in Pediatric Genetics, and the director of the Hamon Laboratory for Stem Cells and Cancer. This work was supported by funding from National Cancer Institute of the National Institutes of Health (NIH) grant number R01 CA166593 and Specialized Programs of Research Excellence (SPORE) grant number U54 CA 196519 to L.Q.L., and NIH grant numbers R37 AG024945 and R01 HL097760 to S.J.M.

\section{References}

Baker JC, Beddington RS, Harland RM. 1999. Wnt signaling in Xenopus embryos inhibits bmp4 expression and activates neural development. Genes Dev 13: 3149-3159.
Belteki G, Haigh J, Kabacs N, Haigh K, Sison K, Costantini F, Whitsett J, Quaggin SE, Nagy A. 2005. Conditional and inducible transgene expression in mice through the combinatorial use of Cre-mediated recombination and tetracycline induction. Nucleic Acids Res 33: e51.

Blanpain C, Fuchs E. 2009. Epidermal homeostasis: a balancing act of stem cells in the skin. Nat Rev Mol Cell Biol 10: 207-217.

Blanpain C, Lowry WE, Geoghegan A, Polak L, Fuchs E. 2004. Self-renewal, multipotency, and the existence of two cell populations within an epithelial stem cell niche. Cell 118: 635-648.

Bosenberg M, Muthusamy V, Curley DP, Wang Z, Hobbs C, Nelson B, Nogueira C, Horner JW II, Depinho R, Chin L. 2006. Characterization of melanocyte-specific inducible Cre recombinase transgenic mice. Genesis 44: 262-267.

Botchkareva NV, Khlgatian M, Longley BJ, Botchkarev VA, Gilchrest BA. 2001. SCF/c-kit signaling is required for cyclic regeneration of the hair pigmentation unit. FASEB $J$ 15: 645-658.

Brannan CI, Lyman SD, Williams DE, Eisenman J, Anderson DM, Cosman D, Bedell MA, Jenkins NA, Copeland NG. 1991. Steel-Dickie mutation encodes a c-kit ligand lacking transmembrane and cytoplasmic domains. Proc Natl Acad Sci 88: 4671-4674.

Chang CY, Pasolli HA, Giannopoulou EG, Guasch G, Gronostajski RM, Elemento O, Fuchs E. 2013. NFIB is a governor of epithelial-melanocyte stem cell behaviour in a shared niche. Nature 495: 98-102.

Chen Z, Liu C, Patel AJ, Liao CP, Wang Y, Le LQ. 2014. Cells of origin in the embryonic nerve roots for NF1-associated plexiform neurofibroma. Cancer Cell 26: 695-706.

Copeland NG, Gilbert DJ, Cho BC, Donovan PJ, Jenkins NA, Cosman D, Anderson D, Lyman SD, Williams DE. 1990. Mast cell growth factor maps near the steel locus on mouse chromosome 10 and is deleted in a number of steel alleles. Cell 63: $175-183$.

Cotsarelis G, Sun TT, Lavker RM. 1990. Label-retaining cells reside in the bulge area of pilosebaceous unit: implications for follicular stem cells, hair cycle, and skin carcinogenesis. Cell 61: 1329-1337.

Coulombe PA, Kopan R, Fuchs E. 1989. Expression of keratin K14 in the epidermis and hair follicle: insights into complex programs of differentiation. J Cell Biol 109: 2295-2312.

Dassule HR, Lewis P, Bei M, Maas R, McMahon AP. 2000. Sonic hedgehog regulates growth and morphogenesis of the tooth. Development 127: 4775-4785.

Decker L, Desmarquet-Trin-Dinh C, Taillebourg E, Ghislain J, Vallat JM, Charnay P. 2006. Peripheral myelin maintenance is a dynamic process requiring constant Krox20 expression. I Neurosci 26: 9771-9779.

Ding L, Saunders TL, Enikolopov G, Morrison SJ. 2012. Endothelial and perivascular cells maintain haematopoietic stem cells. Nature 481: 457-462.

Driskell RR, Clavel C, Rendl M, Watt FM. 2011. Hair follicle dermal papilla cells at a glance. J Cell Sci 124: 1179-1182.

Gambardella L, Schneider-Maunoury S, Voiculescu O, Charnay P, Barrandon Y. 2000. Pattern of expression of the transcription factor Krox-20 in mouse hair follicle. Mech Dev 96: 215-218.

Gokbuget D, Pereira JA, Bachofner S, Marchais A, Ciaudo C, Stoffel M, Schulte JH, Suter U. 2015. The Lin28/let-7 axis is critical for myelination in the peripheral nervous system. Nat Commun 6: 8584 . 
Hayashi S, McMahon AP. 2002. Efficient recombination in diverse tissues by a tamoxifen-inducible form of Cre: a tool for temporally regulated gene activation/inactivation in the mouse. Dev Biol 244: 305-318.

Hsu YC, Pasolli HA, Fuchs E. 2011. Dynamics between stem cells, niche, and progeny in the hair follicle. Cell 144: 92-105.

Hsu YC, Li L, Fuchs E. 2014. Transit-amplifying cells orchestrate stem cell activity and tissue regeneration. Cell 157: 935-949.

Huelsken J, Vogel R, Erdmann B, Cotsarelis G, Birchmeier W. 2001. $\beta$-Catenin controls hair follicle morphogenesis and stem cell differentiation in the skin. Cell 105: 533-545.

Kunisada T, Lu SZ, Yoshida H, Nishikawa S, Nishikawa S, Mizoguchi M, Hayashi S, Tyrrell L, Williams DA, Wang X, et al. 1998a. Murine cutaneous mastocytosis and epidermal melanocytosis induced by keratinocyte expression of transgenic stem cell factor. J Exp Med 187: 1565-1573.

Kunisada T, Yoshida H, Yamazaki H, Miyamoto A, Hemmi H, Nishimura E, Shultz LD, Nishikawa S, Hayashi S. 1998b. Transgene expression of steel factor in the basal layer of epidermis promotes survival, proliferation, differentiation and migration of melanocyte precursors. Development 125: 2915-2923.

Le LQ, Shipman T, Burns DK, Parada LF. 2009. Cell of origin and microenvironment contribution for NF1-associated dermal neurofibromas. Cell Stem Cell 4: 453-463.

Lee P, Morley G, Huang Q, Fischer A, Seiler S, Horner JW, Factor S, Vaidya D, Jalife J, Fishman GI. 1998. Conditional lineage ablation to model human diseases. Proc Natl Acad Sci 95: 11371-11376.

Lennartsson J, Ronnstrand L. 2012. Stem cell factor receptor/cKit: from basic science to clinical implications. Physiol Rev 92: 1619-1649.

Leone DP, Genoud S, Atanasoski S, Grausenburger R, Berger P, Metzger D, Macklin WB, Chambon P, Suter U. 2003. Tamoxifen-inducible glia-specific Cre mice for somatic mutagenesis in oligodendrocytes and Schwann cells. Mol Cell Neurosci 22: 430-440.

Li S, Miao T, Sebastian M, Bhullar P, Ghaffari E, Liu M, Symonds AL, Wang P. 2012. The transcription factors Egr2 and Egr3 are essential for the control of inflammation and antigen-induced proliferation of B and T cells. Immunity 37: 685-696.

Lin JY, Fisher DE. 2007. Melanocyte biology and skin pigmentation. Nature 445: 843-850.

McGill GG, Horstmann M, Widlund HR, Du J, Motyckova G, Nishimura EK, Lin YL, Ramaswamy S, Avery W, Ding HF, et al. 2002 . Bcl2 regulation by the melanocyte master regulator Mitf modulates lineage survival and melanoma cell viability. Cell 109: 707-718.

Nishimura EK, Jordan SA, Oshima H, Yoshida H, Osawa M, Moriyama $M$, Jackson IJ, Barrandon Y, Miyachi Y, Nishikawa S. 2002. Dominant role of the niche in melanocyte stem-cell fate determination. Nature 416: 854-860.

Nishimura EK, Granter SR, Fisher DE. 2005. Mechanisms of hair graying: incomplete melanocyte stem cell maintenance in the niche. Science 307: 720-724.

Nishimura EK, Suzuki M, Igras V, Du J, Lonning S, Miyachi Y, Roes J, Beermann F, Fisher DE. 2010. Key roles for transforming growth factor $\beta$ in melanocyte stem cell maintenance. Cell Stem Cell 6: 130-140.

Okura M, Maeda H, Nishikawa S, Mizoguchi M. 1995. Effects of monoclonal anti-c-kit antibody (ACK2) on melanocytes in newborn mice. I Invest Dermatol 105: 322-328.

Peters EM, Tobin DJ, Botchkareva N, Maurer M, Paus R. 2002. Migration of melanoblasts into the developing murine hair follicle is accompanied by transient c-Kit expression. J Histochem Cytochem 50: 751-766.
Plikus MV, Chuong CM. 2008. Complex hair cycle domain patterns and regenerative hair waves in living rodents. I Invest Dermatol 128: 1071-1080.

Plikus MV, Chuong CM. 2014. Macroenvironmental regulation of hair cycling and collective regenerative behavior. Cold Spring Harb Perspect Med 4: a015198.

Plikus MV, Gay DL, Treffeisen E, Wang A, Supapannachart RJ, Cotsarelis G. 2012. Epithelial stem cells and implications for wound repair. Semin Cell Dev Biol 23: 946-953.

Plikus MV, Mayer JA, de la Cruz D, Baker RE, Maini PK, Maxson R, Chuong CM. 2008. Cyclic dermal BMP signalling regulates stem cell activation during hair regeneration. Nature 451: 340-344.

Rabbani P, Takeo M, Chou W, Myung P, Bosenberg M, Chin L, Taketo MM, Ito M. 2011. Coordinated activation of Wnt in epithelial and melanocyte stem cells initiates pigmented hair regeneration. Cell 145: 941-955.

Reith AD, Rottapel R, Giddens E, Brady C, Forrester L, Bernstein A. 1990. W mutant mice with mild or severe developmental defects contain distinct point mutations in the kinase domain of the c-kit receptor. Genes Dev 4: 390-400.

Saint-Jeannet JP, He X, Varmus HE, Dawid IB. 1997. Regulation of dorsal fate in the neuraxis by Wnt-1 and Wnt-3a. Proc Natl Acad Sci 94: 13713-13718.

Samuelov L, Sprecher E, Tsuruta D, Biro T, Kloepper JE, Paus R. 2012. P-cadherin regulates human hair growth and cycling via canonical Wnt signaling and transforming growth factorß2. J Invest Dermatol 132: 2332-2341.

Schneider-Maunoury S, Topilko P, Seitandou T, Levi G, CohenTannoudji M, Pournin S, Babinet C, Charnay P. 1993. Disruption of Krox-20 results in alteration of rhombomeres 3 and 5 in the developing hindbrain. Cell 75: 1199-1214.

Schouwey K, Delmas V, Larue L, Zimber-Strobl U, Strobl LJ, Radtke F, Beermann F. 2007. Notch1 and Notch2 receptors influence progressive hair graying in a dose-dependent manner. Dev Dyn 236: 282-289.

Sharov AA, Sharova TY, Mardaryev AN, Tommasi di Vignano A, Atoyan R, Weiner L, Yang S, Brissette JL, Dotto GP, Botchkarev VA. 2006. Bone morphogenetic protein signaling regulates the size of hair follicles and modulates the expression of cell cycleassociated genes. Proc Natl Acad Sci 103: 18166-18171.

Shimomura Y, Christiano AM. 2010. Biology and genetics of hair. Annu Rev Genomics Hum Genet 11: 109-132.

Shyh-Chang N, Daley GQ. 2013. Lin28: primal regulator of growth and metabolism in stem cells. Cell Stem Cell 12: 395-406.

Shyh-Chang N, Zhu H, Yvanka de Soysa T, Shinoda G, Seligson MT, Tsanov KM, Nguyen L, Asara JM, Cantley LC, Daley GQ. 2013. Lin28 enhances tissue repair by reprogramming cellular metabolism. Cell 155: 778-792.

Skucas VA, Duffy AM, Harte-Hargrove LC, Magagna-Poveda A, Radman T, Chakraborty G, Schroeder CE, MacLusky NI, Scharfman HE. 2013. Testosterone depletion in adult male rats increases mossy fiber transmission, LTP, and sprouting in area CA3 of hippocampus. J Neurosci 33: 2338-2355.

Solanas G, Benitah SA. 2013. Regenerating the skin: a task for the heterogeneous stem cell pool and surrounding niche. Nat Rev Mol Cell Biol 14: 737-748.

Topilko P, Schneider-Maunoury S, Levi G, Baron-Van Evercooren A, Chennoufi AB, Seitanidou T, Babinet C, Charnay P. 1994. Krox-20 controls myelination in the peripheral nervous system. Nature 371: 796-799.

Tumbar T, Guasch G, Greco V, Blanpain C, Lowry WE, Rendl M, Fuchs E. 2004. Defining the epithelial stem cell niche in skin. Science 303: 359-363. 
Liao et al.

Vasioukhin V, Degenstein L, Wise B, Fuchs E. 1999. The magical touch: genome targeting in epidermal stem cells induced by tamoxifen application to mouse skin. Proc Natl Acad Sci 96: 8551-8556.

Veis DJ, Sorenson CM, Shutter JR, Korsmeyer SJ. 1993. Bcl-2-deficient mice demonstrate fulminant lymphoid apoptosis, polycystic kidneys, and hypopigmented hair. Cell 75: 229-240.

Virador V, Matsunaga N, Matsunaga J, Valencia J, Oldham RJ, Kameyama K, Peck GL, Ferrans VI, Vieira WD, Abdel-Malek ZA, et al. 2001. Production of melanocyte-specific antibodies to human melanosomal proteins: expression patterns in normal human skin and in cutaneous pigmented lesions. Pigment Cell Res 14: 289-297.
Voiculescu O, Charnay P, Schneider-Maunoury S. 2000. Expression pattern of a Krox-20/Cre knock-in allele in the developing hindbrain, bones, and peripheral nervous system. Genesis 26: 123-126.

Watt FM. 2014. Mammalian skin cell biology: at the interface between laboratory and clinic. Science 346: 937-940.

Yoshida H, Kunisada T, Grimm T, Nishimura EK, Nishioka E, Nishikawa SI. 2001. Review: melanocyte migration and survival controlled by SCF/c-kit expression. I Investig Dermatol Symp Proc 6: 1-5.

Zorick TS, Syroid DE, Brown A, Gridley T, Lemke G. 1999. Krox20 controls SCIP expression, cell cycle exit and susceptibility to apoptosis in developing myelinating Schwann cells. Development 126: 1397-1406. 


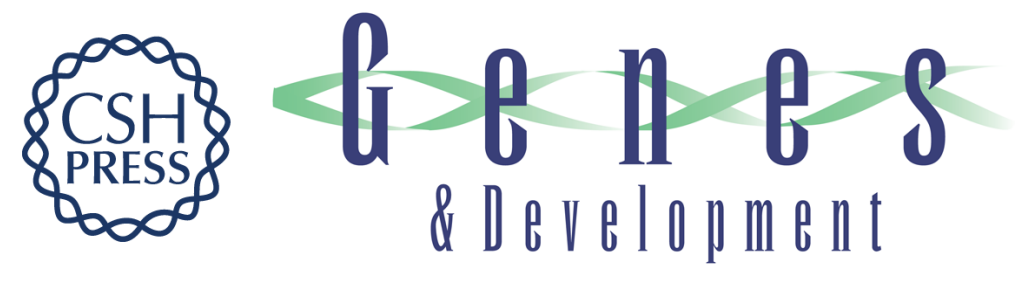

\title{
Identification of hair shaft progenitors that create a niche for hair pigmentation
}

\author{
Chung-Ping Liao, Reid C. Booker, Sean J. Morrison, et al.
}

Genes Dev. 2017, 31: originally published online May 2, 2017

Access the most recent version at doi:10.1101/gad.298703.117

\section{Supplemental http://genesdev.cshlp.org/content/suppl/2017/05/02/gad.298703.117.DC1 \\ Material}

Related Content

Identifying the niche controlling melanocyte differentiation

Manuel Zocco and Cédric Blanpain

Genes Dev. April , 2017 31: 721-723

References This article cites 61 articles, 19 of which can be accessed free at:

http://genesdev.cshlp.org/content/31/8/744.full.html\#ref-list-1

Articles cited in:

http://genesdev.cshlp.org/content/31/8/744.full.html\#related-urls

Creative This article, published in Genes \& Development, is available under a Creative Commons

Commons License (Attribution 4.0 International), as described at

License http://creativecommons.org/licenses/by/4.0/.

Email Alerting
Service $\begin{aligned} & \text { Receive free email alerts when new articles cite this article - sign up in the box at the top } \\ & \text { right corner of the article or click here. }\end{aligned}$

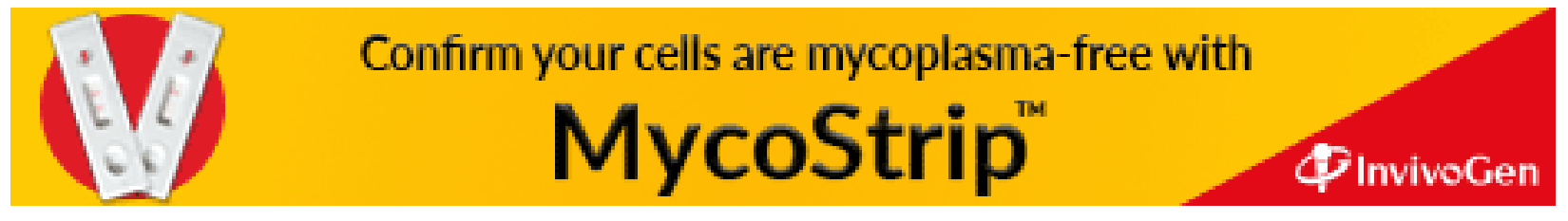

